\title{
Method of Expert Assessment of Stimulation of Field Drying in Milled Peat Harvesting
}

\author{
Elena Chertkova $^{1, *}$, and Victoria Sizova ${ }^{1}$ \\ ${ }^{1}$ Tver State Technical University, 22 Af. Nikitin Emb., 170026, Tver, Russia
}

\begin{abstract}
The article gives the expert assessment data on the selection of the best ways of low-moisture peat harvesting by a milling method. They are essential to reducing the energy expenditure for the artificial drying of peat and ensuring the quality characteristics of raw material required for further thermochemical processing. The R\&D efforts towards stimulation of the field drying of crumb peat are analyzed. The method of prioritization is applied in expert assessment. An appropriate significance rank value is assigned to each method. Mathematical estimate of the expert information reliability is made by the range and the variance of total ranks. The consistency of experts' decisions on the assessment of the milled peat drying stimulation methods was checked by the relative range of significance values as well as the actual and the estimated strength of an expert group. Preference is given to two options: peat drying to harvesting humidity of $35 \%$ in thick layers and that on the slopes of pre-formed swaths of raw peat crumb.
\end{abstract}

\section{Introduction}

On the territory of the Russian Federation there are more than 50 active peat producing companies. According to the statistics data, peat extraction volumes for the last 5 years are 1.5 - 2 million tons per year. The main technological operation involved virtually into all technological processes of advanced processing of peat and distinguished by high energy intensity is an artificial drying of peat to humidity of $12-16 \%[1,2]$. In this regard, the most promising approach is a combination of the solar field drying and the artificial finish drying of peat by means of special drying facilities. At the same time, the specific nature of peat extraction technologies resides in high dependency on weather conditions. This applies to a greater extent to the milling method of crumb peat production. As a rule, the moisture content of the milled fuel peat supplied to a consumer is $45-50 \%$. Let us suppose that the average moisture content of milled peat is $47 \%$, or $0.89 \mathrm{~kg} / \mathrm{kg}$ in terms of wetness; at such initial humidity of peat we have to remove $0.70 \mathrm{~kg}$ of moisture from each kilogram of peat dried at the plant, which is associated with a high consumption of heating energy. This process is associated with the increase of temperature and peat exposure time, which leads to the change in a group chemical composition of peat and the loss of some valuable organic components [3-5].

* Corresponding author: oleg.misnikov@gmail.com 
Thus, the aim of study is to develop a technology for the production of milled peat of no more than $35 \%$ moisture content to provide a maximum quantity of highly mobile bitumen components. This is possible only when we use a method of natural (field) drying of peat. In this regard, literature sources were reviewed for the purpose of identifying the most likely ways to intensify the milled peat drying in field conditions, with the method of expert assessment being applied.

Systematization of the eight main stimulation methods of the natural drying of peat in field conditions [6-10]:

- Thin-layer drying. The technological process provides for the formation of a crumb layer of 7-10 mm thick, drying without turning, harvesting of two / three cycles a day.

- Multiple layer-by-layer drying. The 7-10 mm layer of peat crumb is formed from the preformed swaths of raw peat and spread on the bed surface by a special dryer spreader. Drying to commercial moisture regain is executed without turning. The second raw crumb layer from the swath is spread out on the first dried layer, without turning of the second and first layers. - Provided a good type of drying days, a third layer is spread and dried, followed by the simultaneous harvesting of all layers.

- Drying of compacted grains. In this case, the raw milled mass is sent to a special device to be compacted and formed into "tightened" (coarsened) grains. The grains are spread on the field surface in 1.5-2 layers and dried without turning.

- Drying on the aerated bedding. According to this technological scheme, a peat bed is milled to the depth sufficient for execution of three / four cycles of drying, with the moisture heavily evaporating from the upper layer and the moisture exchange between a layer being dried and an underlying one reducing dramatically.

- Uniform layer drying. The process involves the milling drum modernization by means of special-purpose devices to form a heightwise uniform peat crumb layer.

- Drying of additionally dispersed peat. Intensive bed processing before the extraction of peat is proposed to perform by special machines to the seasonal operating depth, or one technological cycle.

- Drying on the surface of a layer of the previous cycle peat crumb losses. The process involves the creation of special milling machines capable of collecting milled peat losses, their movement to the surface of a bed behind a milling unit, and then the spread of raw crumbs from a milling cutter on the surface of peat crumb losses.

- Drying on the slopes of special swaths. This technological process requires a preliminary formation of large swaths of raw peat crumbs along the length of a map, a milling of the remaining area in each cycle, a drying and a simultaneous harvesting of standard quality products from the surface of swath slopes and the peat bed.

To prevent subjective assessments, the expert assessment methodology was taken for choosing the most effective stimulation methods of milled peat field drying.

\section{Materials and Methods}

The essence of the expert assessment is an intuitive-logical estimation of a problem conducted by experts as well as a formal processing of results and a quantitative evaluation of experts' judgments. The result of creative search is to put forward ideas that are aimed at improving organizational, technological, or technical system.

There exist five stages of expert assessments: a problem statement, an expert group formation, an expert survey, an analysis and processing of expert information, a decisionmaking on the basis of expert review findings.

Basically, pair-wise comparison (correlation), prioritization and Delphi method are used.

Of the three methods mentioned above, prioritization was taken to evaluate the stimulation ways of field peat drying, as being less laborious and involving a quantitative 
assessment in comparison of two ideas. In order to provide an objective justification for choosing the most effective ways of drying stimulation, it was decided to attract famous specialists of science and technology in the field of peat production (Doctors of Engineering Science, professors) from the leading domestic and foreign scientific and educational centers. A special questionnaire was developed and sent to experts. Authors of the indicated peat drying stimulation methods were not involved in expert assessment.

Expert assessment of the milled peat field drying stimulation methods was based on the two following positions: (a) achieving the maximum intensity of field peat drying during the scheduled duration of a cycle; (b) adding the minimal complexity to a technological process and using the maximum quantity of domestic / foreign machines, given their minor modernization.

The method the expert prefers is assigned a greater-than sign (" > "). If the method of drying stimulation, according to the expert, is less significant (preferred), a less than sign $("<")$ is assigned. If two methods are thought to be equal, or the expert has a great deal of difficulty in the assessment, an equal sign (" = ") is put. Then an adjacency matrix is built up. Symbols are replaced by the preference factors: " > $1.5 ; "=" 1 ; "<" 0.5$. An example of processing the results of one of the experts is given in Table 1.

The sum of the preference factors $\sum K_{p}$ is determined for each matrix row. Then the absolute priority $P_{i}$ is calculated: each preference factor $K_{p}$ in the matrix row is multiplied by the column vector of the total values of the preference factors $\sum K_{p}$ of the corresponding method, and then all the products are summed. The significance value is as follows:

$$
\beta_{i}=P_{i} / \sum_{i=1}^{m} P_{i}
$$

where $P_{i}$ is absolute priority for the $i$-th parameter; $m$ is number of methods (ideas).

In accordance with the significance value, an appropriate rank is assigned to each idea (method).

The consistency of experts' decisions on the assessment of the milled peat drying stimulation methods was checked by the relative range of significance values

$$
\Delta \beta_{i}=\frac{{ }_{i j \max }-\beta_{i j \min }}{\beta_{i}} \leq 1.00
$$

where $\beta_{i j \max }, \quad \beta_{i j \min }$ are respectively the maximum and the minimum significance values for the $i$-th method; $\beta_{i}$ is an arithmetic mean significance value.

Table 1. Matrix of adjacency of the crumb peat drying stimulation methods in terms of achieving the maximum intensity.

\begin{tabular}{|l|c|c|c|c|}
\hline \multicolumn{1}{|c|}{ Methods of drying stimulation } & $\begin{array}{c}\text { Sum of } \\
\text { factors, } \\
\Sigma \boldsymbol{\Sigma}_{\boldsymbol{n}}\end{array}$ & $\begin{array}{c}\text { Absolute } \\
\text { priority } \\
\boldsymbol{P}_{\boldsymbol{i}}\end{array}$ & $\begin{array}{c}\text { Significance } \\
\text { value, } \boldsymbol{\beta}_{\boldsymbol{i}}\end{array}$ & $\begin{array}{c}\text { Rank } \\
\boldsymbol{r}_{\boldsymbol{i}}\end{array}$ \\
\hline Thin-layer drying & 6.50 & 47.25 & 0.100 & 6 \\
\hline Multiple layer-by-layer drying & 10.50 & 79.25 & 0.167 & 2 \\
\hline Drying of compacted grains & 6.50 & 46.25 & 0.098 & 7 \\
\hline Drying on the aerated bedding & 7.50 & 54.25 & 0.114 & 4 \\
\hline Uniform layer drying & 4.50 & 34.25 & 0.072 & 8 \\
\hline Drying of additionally dispersed peat & 7.50 & 53.25 & 0.112 & 5 \\
\hline
\end{tabular}




\begin{tabular}{|l|c|c|c|c|}
\hline $\begin{array}{l}\text { Drying on the surface of a layer of the } \\
\text { previous cycle peat crumb losses }\end{array}$ & 9.50 & 69.25 & 0.146 & 3 \\
\hline Drying on the slopes of special swaths & 11.50 & 90.25 & 0.190 & 1 \\
\hline
\end{tabular}

The consistency of experts' decisions on the assessment of the milled peat drying stimulation methods was checked by the relative range of significance values

$$
\Delta \beta_{i}=\frac{\beta_{i j \max }-\beta_{i j \min }}{\beta_{i}} \leq 1.00
$$

where $\beta_{i j \max }, \quad \beta_{i j \min }$ are respectively the maximum and the minimum significance values for the $i$-th method; $\beta_{i}$ is an arithmetic mean significance value.

Calculations of the consistency of expert assessments by a relative range of significance values have shown that all the stimulation methods satisfy the condition $\Delta \beta \leq 1.00$.

Estimation of the expert information confidence was checked by the relative range of total ranks and the variance of total ranks.

The range of total ranks is determined by the formula:

$$
\Delta R=R_{i \max }-R_{i \min }
$$

where $R_{i \max }, R_{i \min }$ are respectively the maximum and the minimum values of the total ranks assigned by experts to all the stimulation methods.

The condition is checked

$$
\Delta \mathrm{R}>\mathrm{m} \sqrt{2 \mathrm{n}}
$$

where $m$ is the number of stimulation methods; $n$ is the expert group strength.

The total rank of the $i$-th method is determined by

$$
R_{i}=\sum_{j=1}^{n} r_{i j}
$$

where $j=1,2,3, \ldots, \mathrm{n}$ is the number of experts; $r_{i j}$ is the rank of the $i$-th stimulation method according to the $j$-th expert estimate.

An approximate estimate is made by the range of total ranks. The more precise estimation of the expert information confidence was carried out by the variance of the total ranks.

$$
\mathrm{D}>(0.22 \mathrm{~m}+0.5) \overline{\mathrm{R}}
$$

where $\bar{R}=\frac{\sum_{i=1}^{m} R_{i}}{m}$ is the arithmetic mean value of the total ranks for all stimulation methods.

According to the formula (3), the left-hand side is as follows: $\Delta R=32.5-7=25.5$

while the right-hand side makes $8 \cdot \sqrt{2 \cdot 5}=25.3$.

The average total rank $\bar{R}=\frac{180}{8}=22.5$.

Dispersion is determined by the formula:

$$
D=\frac{\sum\left(R_{i}-\bar{R}\right)^{2}}{m-1}
$$

$D=\frac{358}{8-1}=51.14$. 
The right-hand side of the formula (6) is as follows: $(0.22 \cdot 8+0.5) \cdot 22.5=50.85$.

Thus, the conditions for the expert information confidence according to the formulas (4), (6) are satisfied.

The actual and the estimated strengths of an expert group were verified. The check was run by significance values of the peat drying stimulation methods. The estimated strength of the expert group was determined by the formula

$$
\mathrm{n}=\frac{\mathrm{C} \overline{\beta_{i}}-\mathrm{B}}{\overline{\beta_{i}}(1-\mathrm{C})}
$$

where $C$ is admissible influence of the judgment of one of the experts on the group assessment.

$\overline{\beta_{i}}$ is an arithmetic mean of significance value for $i$ - th method given by $n$ members of expert review.

$B$ is a possible assessment of an additional expert $(n+1)$.

Given the influence of one expert's judgment on the deviation of the group assessment within $5 \ldots 10 \%$, we have

$/ \beta_{i j}-\overline{\beta_{i}} />\bar{\beta}_{i} \ldots \mathrm{C}=1.05 \ldots 1.10$ (corresponds to $5 \ldots 10 \%$ of influence) and

$/ \beta_{i j}-\bar{\beta}_{i} /<\bar{\beta}_{i} \ldots \mathrm{C}=0.95 \ldots 0.90$ (corresponds to $5 \ldots 10 \%$ of influence)

where $\beta_{i j}$ is a significance value of the $i$-th peat field drying stimulation method according to the $j$-th expert.

We accept that $B$ is a maximum absolute value of the significance difference $B=/ \beta_{i j}-\overline{\beta_{i}} /=\max$.

An arithmetic mean of the significance value is as follows:

$$
\overline{\beta_{i}}=\frac{\sum_{\mathrm{j}=1}^{\mathrm{n}} \beta_{i j}}{\mathrm{n}}
$$

For a thin-layer drying stimulation we have

$$
\begin{aligned}
& / \beta_{i j \max }-\overline{\beta_{i}} /=/ 0.148-0.112 /=0.055 \text { that is less than } \overline{\beta_{i}}(0.055<0.112) \\
& / \beta_{\mathrm{i} j \min }-\overline{\beta_{\mathrm{i}}} /=/ 0.079-0.112 /=0.033 \text { that is less than } \overline{\beta_{i}}(0.033<0.112) .
\end{aligned}
$$

So $B=0.055 ; C=0.90$.

According to the formula (7) the estimated strength of an expert group for one of the drying simulation methods makes

$n=\frac{0.90 \cdot 0.112-0.055}{0.112 \cdot(1-0.90)}=4.08$ persons.

Based on the calculation results, we assume the expert group to be 5 persons strong. The check shows that the actual expert group size is held true; it corresponds to the calculation and does not require the involvement of additional experts.

According to the results of expert assessment, the milled peat field drying stimulation methods were ranked as follows: 1 . Drying on the slopes of special swaths. 2. Drying on the surface of a layer of the previous cycle peat crumb losses. 3. Drying of compacted grains. 45. Drying on the aerated bedding. 4-5. Multiple layer-by-layer drying. 5. Drying of additionally dispersed peat. 7. Thin-layer drying. 8. Uniform layer drying. 


\section{Results and Discussions}

The expert assessment of crumb peat drying stimulation methods allowed us to reasonably recommend the technological process of producing milled peat of lower humidity with the use of pneumatic harvesting machines. We propose to use simultaneously two stimulation drying methods, namely, drying on the aerated bedding and that on the slopes of pre-formed swaths of raw peat crumb. As for the method of aerated bedding drying, we suggest the thickness of the minimum (critical) layer should be $25-30 \mathrm{~mm}$. The previously proposed stimulation method of drying on the aerated bedding, in our opinion, has some drawbacks.

Firstly, to create a 100 - $120 \mathrm{~mm}$ thick spread, special milling drums capable of cutting a peat layer up to $50 \mathrm{~mm}$ deep have to be developed for the implementation of the method in question.

Secondly, the method is based on four cycles of $100-120 \mathrm{~mm}$ layer drying and harvesting. This is only possible if the milled surface makes $20-25 \%$ of the area, not the entire area in each cycle. It is certain to lead to the situation where there will be no area required for peat drying and harvesting in spite of the steady favorable meteorological conditions.

Third, it requires the development and production of special machines for loosening a layer after each cycle.

The method of drying on the surface of a layer of the previous cycle peat crumb losses (2nd rank) and the method of compacted grains drying (3rd rank) were set aside for the following reasons.

The method of milled peat drying on the surface of a layer of the previous cycle peat losses suggests that special milling machines capable of collecting the milled peat losses should be created; the peat deposit should be milled; the previous cycle peat losses should be moved and spread out on the peat bed and then carpeted with the fresh milled crumb material again.

The method of compacted grains drying involves the development of special structures for milling mechanisms to mill peat deposits, with the allowance made to inconsistencies and differences in mechanical stability of peat and to possibility of creating grains of a specified shape and spreading them in an even layer.

These methods of peat drying stimulation do not meet the condition for minimum complexity of a technological process and maximum application of domestic / foreign machines, given their minor modernization.

The proposed method of drying peat crumb in a thick layer, conditionally consisting of two interlayers - the upper parting with the highest evaporating rate and the lower parting which largely prevents the deposit influence on drying. The technology includes the following operations: milling the deposit in the technological cycle after precipitation to a depth of $25-30 \mathrm{~mm}$ with the purpose of forming a layer of $45-50 \mathrm{~mm}$ thick; one or two turnings depending on the category of drying days; harvesting the milled peat with pneumatic machines. Depending on the technical equipment and the real possibilities for modernization of technological machines, a phased introduction of drying stimulation methods is provided. Within the first extraction years it is recommended to dry peat in thick layers on the bed surface. Then, in the course of modernization of pneumatic harvesters and acquisition of equipment for the formation of raw peat swaths, a technological scheme of additional drying on the slopes of raw peat swaths can be implemented.

\section{Conclusion}

Thus, a comprehensive analysis of technological trends in stimulation of milled peat drying in field conditions was carried out. The results of the expert assessment of the peat crumb 
drying stimulation allowed us to recommend a technological process for the milled peat production. It provides for the required quality characteristics for raw materials in regard to moisture (no more than 35\%) and the retention of natural bitumen components in the extracted raw materials. The technology under development involves the simultaneous use of two stimulation methods of drying, namely, deep bed drying and that on the slopes of preformed swaths of raw peat crumb.

\section{References}

1. V. V. Panov, O. S. Misnikov, Mining Journal, 7, 108-112 (2015)

2. B. F. Zyuzin, O. S. Misnikov, V. V. Panov, L. V. Kopenkina, Mining Journal, 5, 73-76 (2013)

3. O. S. Misnikov, E. Yu. Chertkova, Eurasian Mining, 1:21, 63-68 (2014)

4. O. Misnikov, V. Ivanov, E3S Web of Conf., 15, 01017 (2017)

5. O. S. Misnikov, O. V. Dmitriev, V.I . Popov, E. Yu. Chertkova, Polymer Science. Series D, 9:1, 133-139, (2016)

6. V. I. Smirnov, O. S. Misnikov, O. V. Pukhova, Mining Journal, 7, 67-71 (2014)

7. E. Kremcheev, D. Kremcheeva, Research Journal of Pharmaceutical, Biological and Chemical Sciences, 7:3, 1284-1289 (2016)

8. A. E. Afanas'iev, S. N. Gamayunov, O. S. Misnikov, Colloid Journal, 61:3, 274-279 (1999)

9. O. Misnikov, Mires and Peat, 18:22, 1-15 (2016)

10. E. Kremcheev, D. Nagornov, Ecology, Environment and Conservation, 23:2, 956-965 (2017) 